\title{
An Evaluation of Trends in Abundance of Capelin (Mallotus villosus) from Acoustics, Aerial Surveys and Catch Rates in NAFO Division 3L, 1982-89
}

\author{
J. Carscadden, B. Nakashima and D. S. Miller \\ Science Branch, Department of Fisheries and Oceans, P. O. Box 5667 \\ St. John's, Newfoundland, Canada A1C 5X1
}

\begin{abstract}
Trends in capelin (Mallotus villosus) biomass in NAFO Div. 3L during 1982-89 projected from Canadian acoustic surveys were compared to trends in indices of inshore abundance from aerial surveys and trap catch rates. Trends in the two inshore indices of abundance were significantly correlated with each other but were not significantly correlated with the Canadian series. The major differences occurred during 1986 and 1987. Age-compositions in the inshore mature stock were similar to the age-compositions predicted from the acoustic surveys although the latter tended to underestimate the proportions of older fish. The time series was short and the relationships tested were not always statistically significant, however, the general agreement in trends of all indices engendered confidence in the approach and especially in the acoustic surveys which provide absolute abundance indices which can be used directly for management advice.
\end{abstract}

Key words: Abundance, acoustics, aerial surveys, catch rates, capelin

\section{Introduction}

Over the last 20 years or so, methods of fish stock assessment have developed rapidly in response to increased fishing pressure and the need for accurate evaluation of a safe level of fishing. Techniques to assess the abundance of a species can take many forms, direct or indirect (e.g. acoustic surveys and virtual population analysis (VPA), respectively), but inevitably there is a desire to validate the estimates of abundance. Often the validation takes the form of comparison of different estimates or indices of abundance. When a series of abundance estimates are compared, similar trends over time promote confidence both in the methods and results but differing trends between series prompt the investigator to determine why the differences are occurring

In this paper, we examine the comparability of indices of abundance for one stock of capelin (Mallotus villosus) in the Northwest Atlantic, viz. that in NAFO Div. 3L during 1982-89. We compare trends in biomass projected from acoustic surveys with indices of abundance from a commercial catchrate series and an aerial survey.

\section{Background}

Capelin is a small (maximum size about 200 $\mathrm{mm}$ ), silvery pelagic fish species, circumpolar in distribution in northern waters (Jangaard, 1974). On the east coast of North America, capelin is abundant in the waters surrounding Newfoundland and
Labrador, where five major stocks (Campbell and Winters, 1973) have been designated for management purposes (Fig. 1). Three of these stocks (NAFO Subarea 2 and Div. 3K, Div. 3L and Div. 3NO) have been subjected to directed fisheries and have been the object of scientific research since the early1970s. This contribution deals only with the Div. 3L stock.

The northern Grand Bank is a nursery and overwintering area for this stock (Carscadden, 1983). Maturation begins in the offshore area in latewinter and early-spring and then these maturing fish migrate inshore to spawn during late-June and early-July. Most spawning occurs intertidally on gravel beaches during a 4-6 week period at water temperatures of $5.5^{\circ}$ to $8.5^{\circ} \mathrm{C}$ but when water temperatures become too high, spawning may take place in deeper water adjacent to beaches (Templeman, 1948). The bulk of the mature capelin stock is 3 and 4 years of age. Spawning mortality is high, estimated to be greater than $80 \%$ (Carscadden and Miller, MS 1980).

Prior to the 1970s, a local inshore capelin fishery was prosecuted for bait and fertilizer (Carscadden, 1983). During the early-1970s, the commercial catch of capelin rose with increasing midwater trawler effort concentrating in the offshore zone (outside 12 naut. miles) during March-May. Catches peaked at 58000 tons in 1974 and then declined to 25000 tons in 1978, after which the offshore fishery was terminated. In the late-1970s, an 


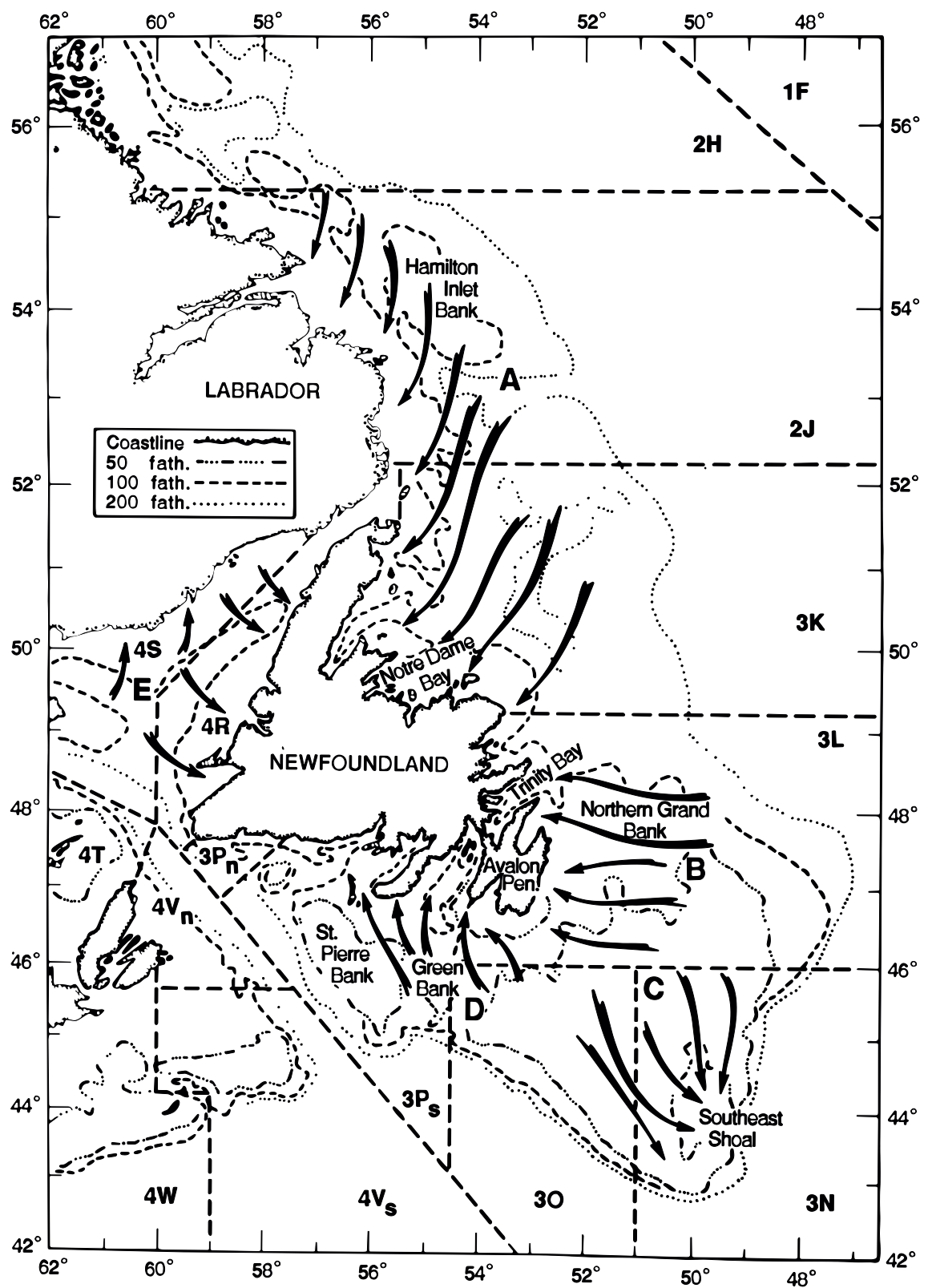

Fig. 1. Map showing major capelin stocks (A-E) and spawning migration routes of capelin in the Northwest Atlantic.

Key to stocks: $\mathbf{A}$ - Labrador/Northeast Newfoundland (NAFO Div. 2J3K) stock; B - Northern Grand Bank/Avalon (NAFO Div. 3L) stock; C - South Grand Bank (Southeast Shoal - NAFO Div. 3NO) stock; D - St. Pierre Bank (NAFO Subdiv. 3Ps) stock; and $\mathbf{E}$ - Gulf of St. Lawrence stock.

inshore fishery directed at roe-bearing females developed. The primary gears used in this fishery have been purse seines and trap nets. Catches in this inshore fishery during 1978-90 ranged from 6400 tons to 53000 tons with the peak catch occurring in 1988. Management has been by quota; final quotas are determined by market requirements and in the years addressed in this paper have generally been lower than advised from results of scientific assessments.

The biology of capelin and the pattern of the fishery have influenced the type of biological research used as the basis of advice for management of this stock. Estimation of capelin biomass using sequential population models has proven problematic 
because of the short life span (capelin older than 4 years comprise less than $10 \%$ of the population) and high spawning mortality. The changing nature of the fishery from an offshore midwater trawler fishery to an inshore purse seine and trap fishery prompted us to incorporate fishery-independent assessment methodologies. Because the mature biomass is dominated by two age-groups (3-and 4-year-olds) and the present inshore fishery is directed at mature fish, the primary objective of annual assessments of this stock has been to estimate the relative strength of year-classes which will recruit to the fishery the following year. These recruiting yearclasses have been estimated annually since 1982 from data collected during hydroacoustic surveys in spring in offshore nursery areas in Div. 3L.

While the acoustic survey results have formed the basis for assessing this capelin stock, other techniques have been used to monitor trends in abundance of the mature stock during the inshore spawning period and thereby evaluate the projections based on the acoustic survey data. Two indices of inshore abundance have been developed: catch rates from trap nets and an index of relative spawning biomass estimated from aerial photographs of capelin schools near spawning beaches.

\section{Materials and Methods}

\section{Acoustic survey methodology}

Hydroacoustic surveys have been conducted offshore in NAFO Div. 3L during spring (April-May) since 1982. The timing of the surveys has varied somewhat during the 1982-88 period. During 198284 inclusive, surveys were conducted in April but it was found that in some years, ice created problems in towing the transducer. Thus, beginning in 1985, the survey was moved to May to avoid ice and the survey period was extended allowing greater areal coverage (Table 1). An example of the design of a recent survey is shown in Fig. 2.

All acoustic cruises were conducted from the RV Gadus Atlantica, a $73.5 \mathrm{~m}$ stern trawler. The transducer was mounted in an underwater vehicle and towed behind the vessel to minimize ship noise and turbulence. Acoustic data were collected using a Simrad EK 400 echosounder operating at 49 Khz with a pulse length of 0.4 milliseconds in 1982 , 0.3 milliseconds in 1983, and 0.6 milliseconds since 1984 , and a band width of $3.3 \mathrm{Khz}$. A time-variedgain of $20 \log R+2 \alpha R(\alpha=0.0120 \mathrm{~dB} / \mathrm{m})$ was used. Returned echo signals were demodulated and fed to a custom-designed microprocessor-controlled hydroacoustic data acquisition system (HYDAS) (Stevens, 1986).
A hydroacoustic data acquisition system was calibrated by measuring the transmit and receive performance of the system with a hydrophone. Prior to performing the measurements, the hydrophone was calibrated by Canadian Department of Defense personnel by comparison with a standard hydrophone.

The calibration exercise was initialized by mounting the transducer selected for a survey in the underwater towed vehicle. The vehicle was attached to the top end of a mechanical frame and the hydrophone was secured to a pedestal mounted at the bottom end of the frame. A measuring tape was used to measure the distance between the hydrophone and the face of the transducer.

An articulating crane was used to lower the frame over the side of the vessel. The frame was immersed in water until the transducer was at a depth of approximately $2 \mathrm{~m}$.

The echosounder and the associated instrumentation required to conduct the calibration were configured to measure the received response of the system. With the hydrophone emitting acoustic pulses of known amplitude, the location of the pedestal containing the hydrophone was moved by small increments. The voltage at the output of the echosounder receiver was observed and the hydrophone was assumed to be aligned with the acoustic axis of the transducer when the voltage was maximized.

After locating the acoustic axis, the voltage output from the receiver was measured and the receiving sensitivity for the system was calculated. Then, the system was configured to transmit acoustic pulses. The voltage output from the hydrophone was measured and the source level was computed. A calibration value for the system was obtained by adding the source level and the receiving sensitivity values.

The survey area was subdivided into discrete blocks (Fig. 2) based on results from earlier exploratory surveys and the bathymetry of the area. A systematic zigzag cruise track was chosen to acoustically sample the survey blocks (Kimura and Lemberg, 1981; Nakashima, MS 1981) and density estimates were calculated using a cluster sampling model (Nakashima, MS 1981; Williamson, 1982).

Length and age compositions were derived from catches using either an Engels or Diamond IX midwater trawl with a codend liner of mesh size not exceeding $12 \mathrm{~mm}$. Midwater trawl fishing sets were made on an opportunistic basis. To achieve a bal- 
TABLE 1. Mean densities ( $\mathrm{g} \cdot \mathrm{m}^{-2}$ ), area $\left(\mathrm{km}^{2}\right)$, biomass (t), and by survey block and abundance estimates (billions) of immature and mature capelin for spring offshore acoustic surveys on Gadus Atlantica in NAFO Div. 3L, 1982-88.

\begin{tabular}{|c|c|c|c|c|c|c|c|c|c|}
\hline $\begin{array}{l}\text { Survey } \\
\text { and date }\end{array}$ & $\begin{array}{l}\text { Survey } \\
\text { block }\end{array}$ & $\begin{array}{l}\text { Mean } \\
\text { density }\end{array}$ & Area & Biomass & Age & 2 & 3 & 4 & $5+$ \\
\hline $\begin{array}{l}\text { GADUS } 64 \\
\text { April } 1982\end{array}$ & $\begin{array}{l}A \\
B \\
C \\
D\end{array}$ & $\begin{array}{r}2.31 \\
16.73 \\
1.49 \\
3.57\end{array}$ & $\begin{array}{r}9483 \\
19002 \\
20854 \\
26398 \\
75737\end{array}$ & $\begin{array}{r}21906 \\
317903 \\
31072 \\
94241 \\
465122\end{array}$ & $\begin{array}{l}\text { Imm. } \\
\text { Mat. }\end{array}$ & $\begin{array}{l}9.0 \\
0.7\end{array}$ & $\begin{array}{r}3.1 \\
13.1\end{array}$ & $\begin{array}{l}0.1 \\
2.3\end{array}$ & $0 . \overline{8}$ \\
\hline $\begin{array}{l}\text { GADUS } 77 \\
\text { April } 1983\end{array}$ & $\begin{array}{l}B \\
C \\
D\end{array}$ & $\begin{array}{l}1.25 \\
0.86 \\
5.90\end{array}$ & $\begin{array}{r}12279 \\
12685 \\
9960 \\
34924\end{array}$ & $\begin{array}{l}15349 \\
10909 \\
58764 \\
85202\end{array}$ & $\begin{array}{l}\text { Imm. } \\
\text { Mat. }\end{array}$ & $\begin{array}{l}2.9 \\
0.5\end{array}$ & $\begin{array}{l}0.7 \\
1.2\end{array}$ & $0 . \overline{8}$ & $0 . \overline{1}$ \\
\hline $\begin{array}{l}\text { GADUS } 93 \\
\text { April/May } 1984\end{array}$ & $\begin{array}{l}\text { A } \\
B\end{array}$ & $\begin{array}{r}15.87 \\
2.68\end{array}$ & $\begin{array}{l}18080 \\
25220 \\
43300\end{array}$ & $\begin{array}{r}286930 \\
67590 \\
354520\end{array}$ & $\begin{array}{l}\text { Imm. } \\
\text { Mat. }\end{array}$ & $\begin{array}{r}19.3 \\
1.8\end{array}$ & $\begin{array}{l}1.0 \\
5.3\end{array}$ & $3 . \overline{1}$ & $0 . \overline{5}$ \\
\hline $\begin{array}{l}\text { GADUS } 109 \\
\text { May } 1985\end{array}$ & $\begin{array}{l}A \\
B \\
C \\
D \\
E \\
F\end{array}$ & $\begin{array}{r}63.8 \\
153.8 \\
215.2 \\
43.6 \\
28.4 \\
24.1\end{array}$ & $\begin{array}{r}5162 \\
4662 \\
5464 \\
6817 \\
23345 \\
10770 \\
56220\end{array}$ & $\begin{array}{r}329336 \\
717016 \\
1175853 \\
297221 \\
662998 \\
259557 \\
3441981\end{array}$ & $\begin{array}{l}\text { Imm. } \\
\text { Mat. }\end{array}$ & $\begin{array}{r}359.1 \\
10.5\end{array}$ & $\begin{array}{l}45.5 \\
34.9\end{array}$ & $3 . \overline{4}$ & $2 . \overline{3}$ \\
\hline $\begin{array}{l}\text { GADUS } 124 \\
\text { May } 1986\end{array}$ & $\begin{array}{l}A \\
B \\
C \\
D\end{array}$ & $\begin{array}{r}139.7 \\
36.5 \\
37.4 \\
23.8\end{array}$ & $\begin{array}{r}10715 \\
19686 \\
33812 \\
9106 \\
73319\end{array}$ & $\begin{array}{r}1486886 \\
718539 \\
1264569 \\
216723 \\
3696717\end{array}$ & $\begin{array}{l}\text { Imm. } \\
\text { Mat. }\end{array}$ & $\begin{array}{r}59.0 \\
0.4\end{array}$ & $\begin{array}{l}99.9 \\
58.1\end{array}$ & $\begin{array}{r}1.4 \\
19.9\end{array}$ & $0 . \overline{7}$ \\
\hline $\begin{array}{l}\text { GADUS } 137 \\
\text { May-June } 1987\end{array}$ & $\begin{array}{l}A \\
B \\
C \\
D\end{array}$ & $\begin{array}{l}35.6 \\
13.8 \\
44.0 \\
46.9\end{array}$ & $\begin{array}{r}10715 \\
19686 \\
33812 \\
9255 \\
73468\end{array}$ & $\begin{array}{r}381454 \\
271667 \\
1487728 \\
434060 \\
2574909\end{array}$ & $\begin{array}{l}\text { Imm. } \\
\text { Mat. }\end{array}$ & $\begin{array}{r}82.9 \\
5.2\end{array}$ & $\begin{array}{r}4.9 \\
13.4\end{array}$ & $\begin{array}{r}0.9 \\
38.1\end{array}$ & $3 . \overline{-}$ \\
\hline $\begin{array}{l}\text { GADUS } 151 \\
\text { May } 1988\end{array}$ & $\begin{array}{l}A \\
B \\
C \\
D\end{array}$ & $\begin{array}{r}55.7 \\
121.7 \\
49.4 \\
36.4\end{array}$ & $\begin{array}{l}10715 \\
19686 \\
10897 \\
28029 \\
69327\end{array}$ & $\begin{array}{r}596302 \\
2396305 \\
538517 \\
1019350 \\
4550474\end{array}$ & $\begin{array}{l}\text { Imm. } \\
\text { Mat. }\end{array}$ & $\begin{array}{r}373.0 \\
7.4\end{array}$ & $\begin{array}{l}15.6 \\
50.1\end{array}$ & $\begin{array}{l}0.1 \\
9.6\end{array}$ & $\begin{array}{r}0.1 \\
16.7\end{array}$ \\
\hline
\end{tabular}

ance between acoustic survey time and fishing time, fishing was performed only when pelagic fish were detected, no more than twice per day and no more than once per transect unless the schooling patterns changed. Random length samples of 200 capelin were taken from each fishing set. Stratified age samples were taken from each length sample and combined for an age-length key. Total age composition was calculated by weighting the sampling data for each survey block by the acoustic abundance estimate for that block.

Since the survey utilized a single beam hydroacoustic system, in situ target strength estimates could not be derived. A target strength/length regression was derived experimentally for Newfoundland capelin (U. Buerkle, St. Andrews Biological Station, St. Andrews, N. B., pers. comm.). When a length-weight relationship was combined with the target strength-length regression, the target strength per kilogram was within $\pm 0.5 \mathrm{~dB}$ of $-34 \mathrm{~dB} /$ $\mathrm{kg}$. This was well within the range of variation in the length sample data $(10-20 \mathrm{~cm})$ used to determine target strength. As a result a target strength value of $-34 \mathrm{~dB} / \mathrm{kg}$ was used in the analysis.

Digitized acoustic data were analyzed by squaring the sample voltage (rms) levels and averaging over $1 \mathrm{~m}$ depth intervals. Data were accumulated and averaged over 10-min intervals at constant boat 


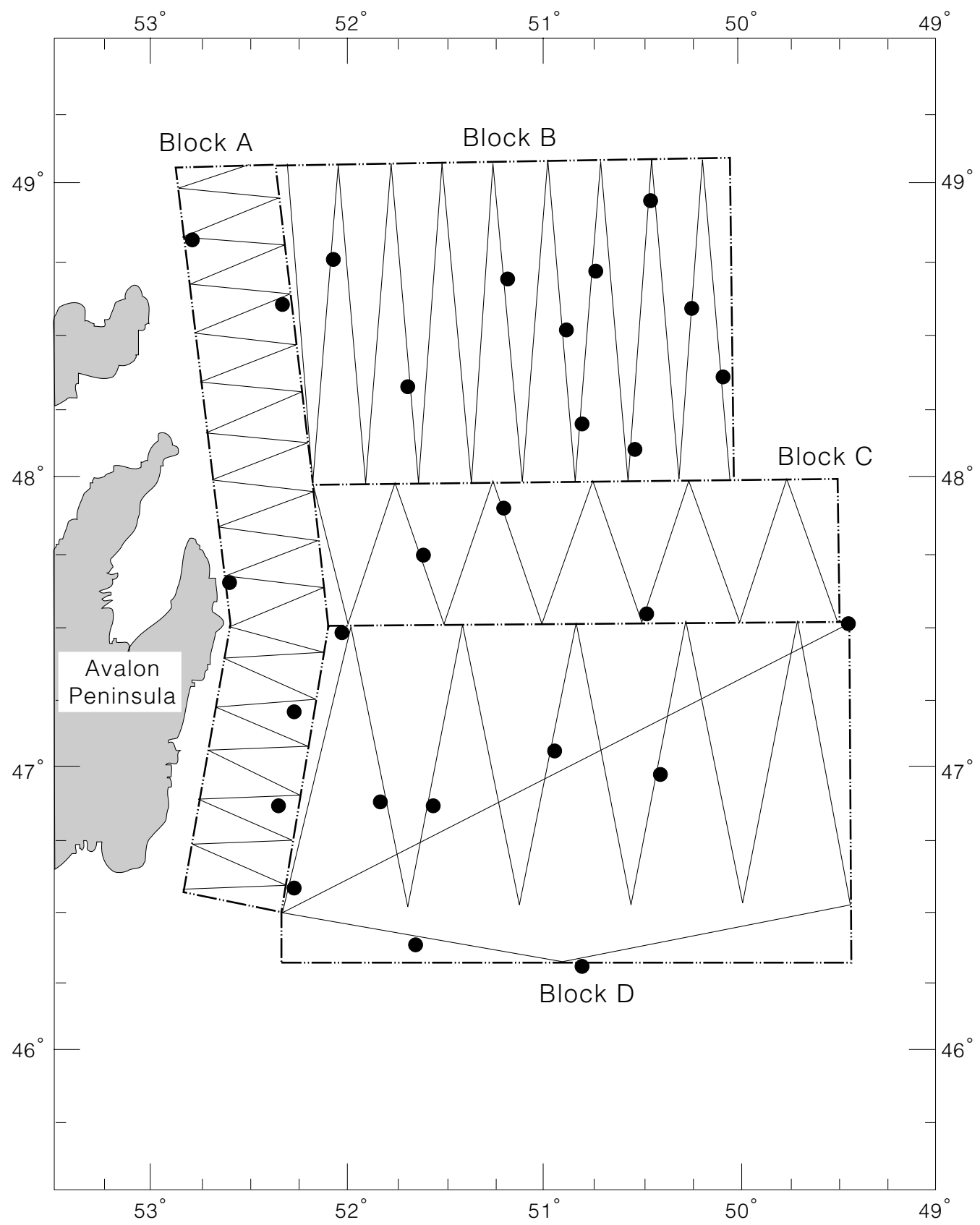

Fig. 2. Example of an acoustic survey track and fishing set locations. This survey was Gadus Atlantica Cruise No. 151 conducted during May 1988.

speed corresponding to a survey track distance of $3.1 \mathrm{~km}$. The density per cubic meter $(\lambda)$ for depth $\mathrm{R}$ was then calculated from:

$$
\begin{aligned}
& \lambda=\mathrm{V}_{\mathrm{R}}^{2} \mathrm{~K} \\
& \text { where } K=10^{\left(-R x+10+\bar{b}+T S+G o+10 \log \left(\frac{1}{2} C t\right)\right) / 10}
\end{aligned}
$$

where $\quad V_{R}^{2}$ is the average rms voltage squared at depth $R$,

$R x$ is the receiving sensitivity of the trans- ducer $(\mathrm{dB})$,

lo is the rms transmitted intensity level $(\mathrm{dB})$,

$\bar{b}$ is the average beam pattern $(d B)$,

TS is the target strength $(d B)$,

$\mathrm{C}$ is the speed of sound in seawater, $t$ is the pulse length of the transmitted pressure level,

and $\quad G o$ is the fixed (depth independent) gain of the echosounder (dB). 
The weight of fish $(\mathrm{g})$ per $\mathrm{m}^{2}$ of surface area was then calculated by summing the individual densities per $\mathrm{m}^{2}$ over the depth range. If sampling within the survey block indicated the presence of other species in the acoustic sample, the density estimate was adjusted proportionally to the percentage by weight of capelin in the midwater trawl samples. An average density estimate was then calculated from these individual estimates for the entire survey block. Total biomass for the block was calculated by applying the mean block density to the total surface area of the block.

A biomass estimate for the entire survey area was calculated by summation of survey block biomass estimates.

We have used the estimates of abundance by age-groups, projected the numbers forward one year and calculated the mature biomass from the projected numbers. Although the timing of the spring surveys varied between late-April and earlyJune, for purposes of these projections we have assumed the acoustic estimates were made for 1 June each year. We have also assumed that spawning time is 1 June. All projection parameters are the same as used in the scientific assessment process of NAFO (see e.g. NAFO, 1989). Estimates of spawning mortality for each age (Carscadden et al., 1985), values of proportions mature (Carscadden et al., MS 1981), and mean weights by age group from inshore sampling data (Table 2) have been estimated while natural mortality rate, other than spawning mortality, has been assumed and set equal to 0.3 .

\section{Aerial survey}

All aerial survey flights were along the coastline following a defined survey track in Conception and Trinity Bays, Newfoundland (Fig. 3). These bays were chosen as the study sites because they are in the central area of the Div. 3L stock, the fishery has consistently high landings in these bays and both are within 1 hour of flying time from the nearest airport at St. John's, Newfoundland.

TABLE 2. Estimates of capelin spawning mortality, values of proportions mature and mean weights by age group used in projections.

\begin{tabular}{lccc}
\hline \hline Age & $\begin{array}{c}\text { Spawning } \\
\text { mortality }\end{array}$ & $\begin{array}{c}\text { Proportions } \\
\text { mature }\end{array}$ & $\begin{array}{c}\text { Mean weights } \\
(\mathrm{g})\end{array}$ \\
\hline 3 & 1.39 & 0.47 & 21.2 \\
4 & 1.69 & 0.87 & 28.4 \\
5 & 2.23 & 0.93 & 31.1 \\
6 & $2.23^{\mathrm{a}}$ & 1.00 & 32.4 \\
\hline
\end{tabular}

a Assumed to be the same as age 5 .
All surveys used fixed wing aircraft with a large format camera and $228 \times 228 \mathrm{~mm}$ aerocolour negative 2445 film which penetrates water to a depth visible to the naked eye. An anti-vignetting filter was used in all years.

Two observers along with a pilot and navigator/ photographer were present on all flights. One observer spotted capelin schools and directed the pilot during the survey while the other recorded relevant information. Optimal photographic conditions were on sunny days with light wind conditions. To minimize glare, reduce the effect of land shadows along the coastline, and increase visibility, photographs were generally taken when the sun angle was between $20^{\circ}$ and $45^{\circ}$. The optimal flying altitude was set at $457 \mathrm{~m}(1500 \mathrm{ft})$ above sea level. An accurate measurement of altitude is essential to estimate the scale of each photograph and consequently, a radar altimeter has been used for all surveys since 1983.

Because the distribution of capelin varied somewhat within and between bays, the survey track was subdivided into four survey transects (Fig. 3). One transect in Trinity Bay encompassed the route from the Horse Chops to Gooseberry Cove including Southwest Arm, while the second ran from Gooseberry Cove to Hopeall. One transect in Conception Bay included the shoreline from Caplin Cove to Harbour Grace Islands and the other transect went from Harbour Grace Islands to Portugal Cove. It was impractical to survey the entire coastline of both bays within the optimal time period each day. Thus difficult areas to survey, areas with low landings, and places with no fixed gear fishing were excluded from the survey track. The flight path represented the maximum area which could be covered on an ideal day under optimal photographic conditions, when capelin were abundant and widely dispersed inshore.

We attempted to complete at least one transect on each flight. Flights generally alternated between bays. When a school was observed, it was photographed and location, altitude and time of day were recorded. Photographic frames overlapped by 10$20 \%$ and contained some shoreline as a reference point for later identification. The frequency of flights was increased subject to weather to cover the peak periods of capelin abundance inshore.

Each photograph was visually scanned to identify capelin schools against a background of kelp beds and rock formations. Capelin schools were usually easily identified because of their greyish colour and distinctive shapes. School surface area was measured using a compensating polar planimeter. The scale (RF) of the photography was 


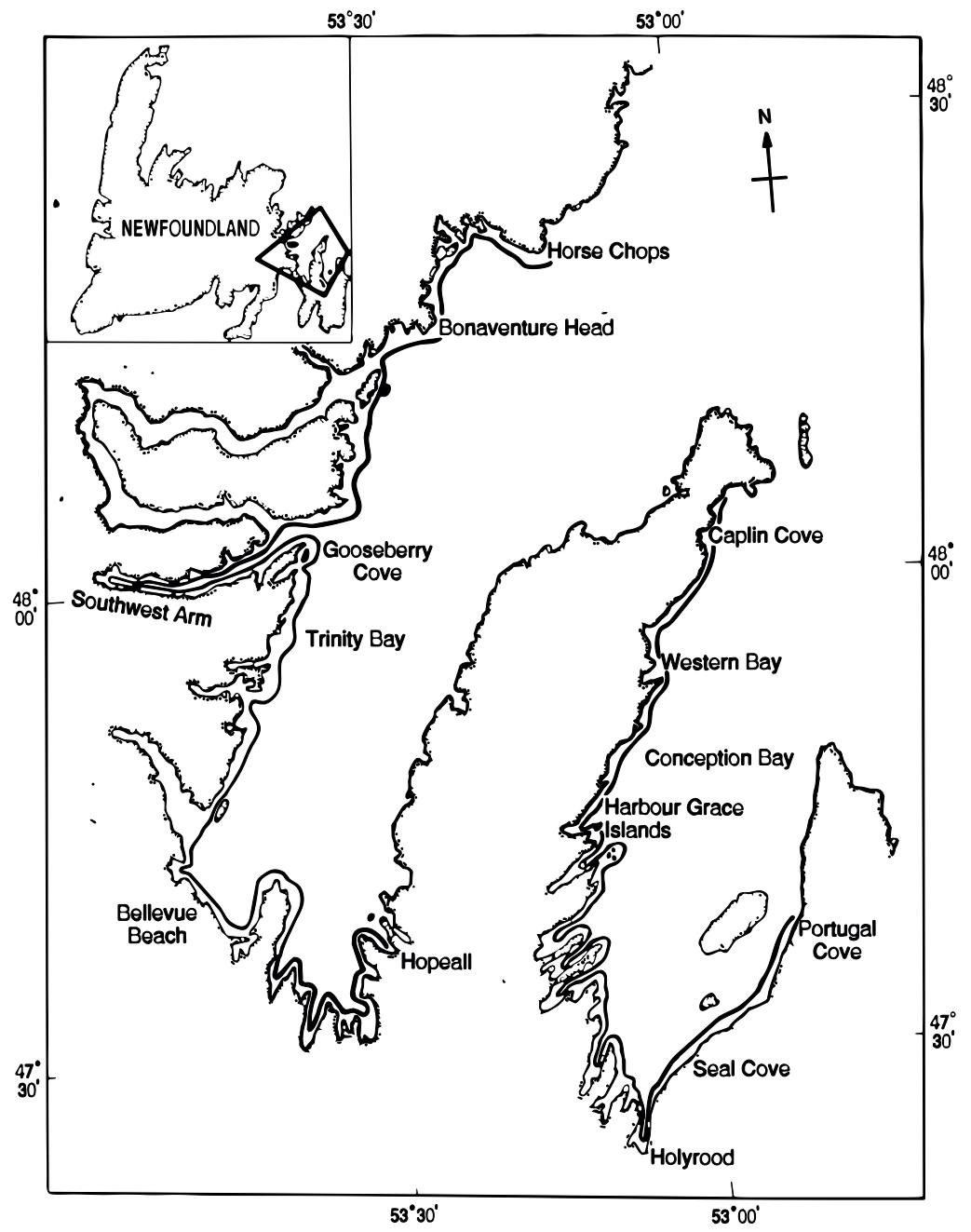

Fig. 3. Aerial survey transects in Conception and Trinity Bays. Transects are from Horse Chops to Gooseberry Cove to Hopeall in Trinity Bay and from Caplin Cove to Harbour Grace Islands, Harbour Grace Islands to Portugal Cove in Conception Bay.

estimated by the equation $R F=F / A$ where $F$ is focal length in $\mathrm{cm}$ and $A$ is the altitude in $\mathrm{cm}$. Each school was measured three times by the same person and the average of the three measurements was accepted as the estimated school size. Only complete transects were included in the analysis. The total observed surface area was calculated per transect and assumed to represent a minimum estimate of available school surface area. No density or school depth measurements are available, and in this analysis it is assumed that all schools were of uniform density.

An annual relative abundance index was calculated by summing the highest total capelin surface area observed along each of the four transects.

\section{Catch rates from research logbooks}

Specially designed research logbooks have been distributed since 1981 to a subsample of commercial trap net fishermen who were asked to record detailed catch and effort data. Details of the procedures to select fishermen to provide good spatial coverage are given in Nakashima (MS 1984).

During 1981-85, fishermen were visited personally to explain how to complete the logbook, to review their performance and discuss problems. This degree of personal contact has been reduced in later years because of confidence in the quality of the data but most fishermen are still contacted after the fishery. The research logbook data are superior to purchase slip data because they include 
discards and whether dead or live fish are discarded.

Random samples were collected weekly from each gear type in the commercial capelin fishery in major bays in Div. 3L. From each sample of 200 fish measured for length, a stratified sample of otoliths for ageing was collected on the basis of 2 fish per sex per $0.5 \mathrm{~cm}$ length group.

\section{Results}

\section{Acoustic surveys}

During the first 3 years of the survey series, the biomass estimates were lower than during the last 4 years (Table 1). While these differences may be due in part to the area covered, especially in 1983 and 1984, densities during the earlier period were also lower.

Estimates of abundance by age-group from the acoustic surveys indicated that the 1983 year-class was relatively strong at all ages from 2 to 5 . The estimate of the 1986 year-class at age 2 was also high suggesting that this year-class might also be strong.

Results of the projections using estimates of abundance from Table 1 and parameters in Table 2 are given in Table 3 and shown in Fig. 4.

The predicted age compositions of mature fish (Table 3) show a predominance of age 3 fish in each year except 1987 when age 4 fish predominated. The contribution of older fish (ages 5 and 6) was not strong (usually less than 10\%).

\section{Aerial survey}

Annual coverage by the aerial survey has been variable due to changing flying conditions. The worst year was 1986 (Table 4) when weather conditions were consistently bad resulting in only 5 days of survey totalling $13.4 \mathrm{hr}$ compared to the 198389 (omitting 1986) average of 9 days and $28.7 \mathrm{hr}$ of survey. Also no estimate was available for one transect during 1986.

Since the highest value of school surface area in each transect is summed to provide the annual index, the 1986 index is likely an underestimate of the true capelin abundance that year.

Based on the school surface area indices, the capelin abundance spawning inshore was relatively low during 1982, 1984 and 1986 and highest during 1987 (Table 4, Fig. 4).

\section{Inshore catch rates}

The trap catches have increased in importance in the inshore fishery, accounting for less than half of the inshore landings from 1982 to 1984, to about two-thirds of the landings in the last 4 years (Table 5 ). Total catches of capelin inshore have also increased in recent years due to a larger share of the limited Japanese market.

The trap net catch rates show a general increase over the series (Fig. 4). The 1987 estimate

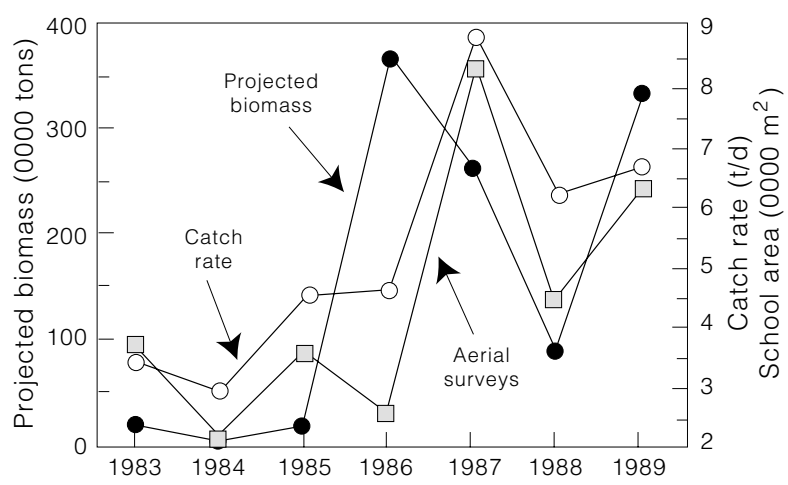

Fig. 4. Trends in capelin indices of abundance from aerial surveys, and catch rates from traps, and trends in projected mature biomass from Canadian acoustic surveys, 1983-89.

TABLE 3. Age composition and biomass of mature capelin predicted from acoustic surveys and age compositions from inshore capelin fishery, all gears, 1983-89. Age compositions in parentheses are calculated excluding 2-year-olds.

\begin{tabular}{|c|c|c|c|c|c|c|c|c|c|c|c|c|c|c|}
\hline \multirow[b]{2}{*}{ Age } & \multicolumn{2}{|c|}{1983} & \multicolumn{2}{|c|}{1984} & \multicolumn{2}{|c|}{1985} & \multicolumn{2}{|c|}{1986} & \multicolumn{2}{|c|}{1987} & \multicolumn{2}{|c|}{1988} & \multicolumn{2}{|c|}{1989} \\
\hline & Pred. & Actual & Pred. & Actual & Pred. & Actual & Pred. & Actual & Pred. & Actual & Pred. & Actual & Pred. & Actual \\
\hline 2 & & 5 & & 2 & & 12 & & & & 4 & & 11 & & 1 \\
\hline 3 & 60 & $61(64)$ & 66 & $40(40)$ & 91 & $61(70)$ & 81 & 62 & 24 & 18 (19) & 88 & $59(66)$ & 73 & $76(77)$ \\
\hline 4 & 39 & 33 (34) & 32 & $54(55)$ & 8 & 20 (23) & 19 & 34 & 75 & $73(76)$ & 10 & $15(17)$ & 26 & $21(21)$ \\
\hline 5 & 1 & $2(2)$ & 1 & $5(5)$ & 1 & $6(7)$ & - & 3 & 1 & $5(5)$ & 2 & $14(16)$ & 1 & $1(1)^{\prime}$ \\
\hline 6 & - & - & - & - & - & - & - & - & - & - & - & $1(1)$ & - & $1(1)$ \\
\hline $\begin{array}{l}\text { Predicted } \\
\text { mature } \\
\text { biomass } \\
\text { ('000 t) }\end{array}$ & 206 & & 46 & & 201 & & 3683 & & 2642 & & 952 & & 3363 & \\
\hline
\end{tabular}




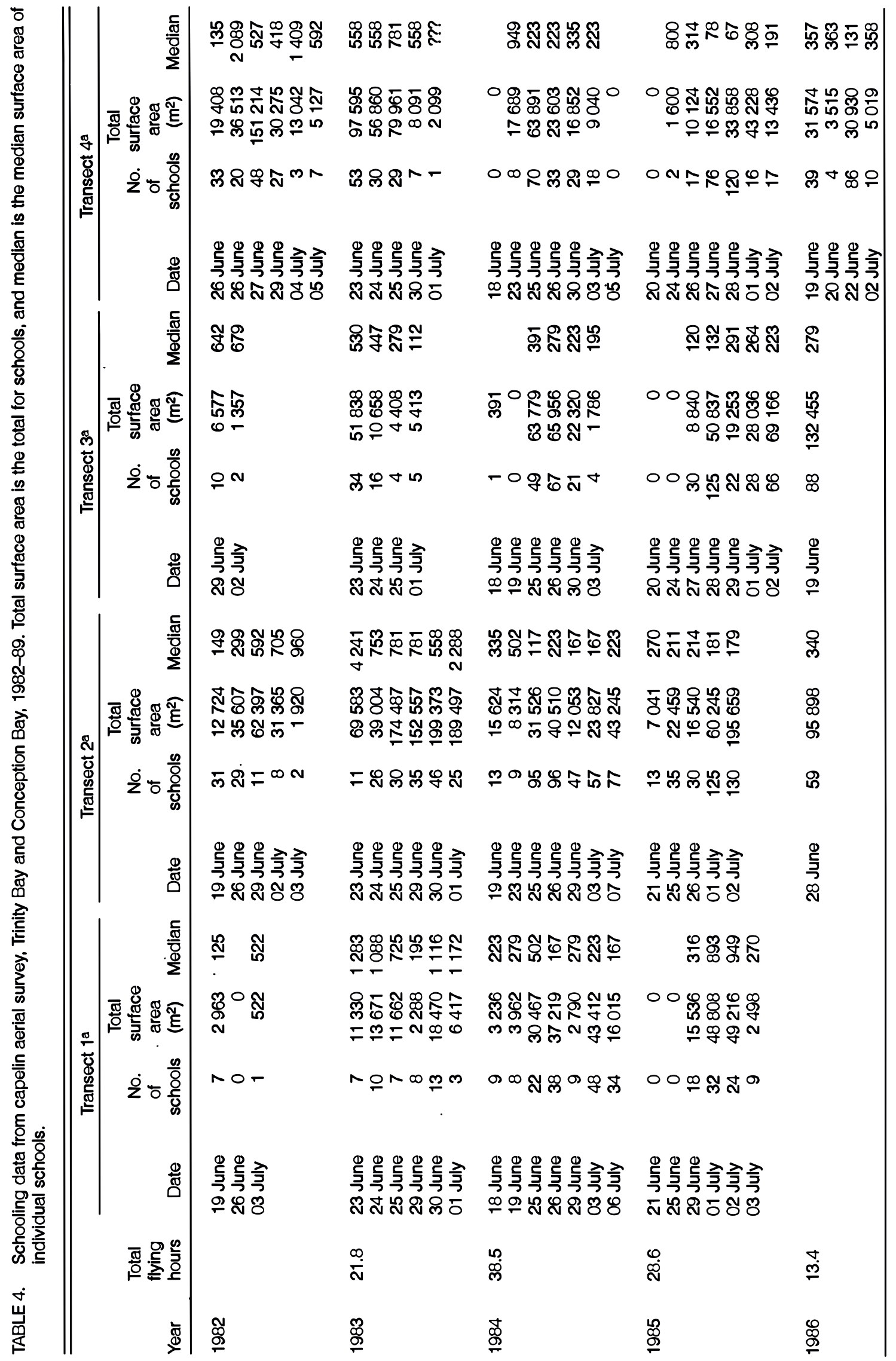




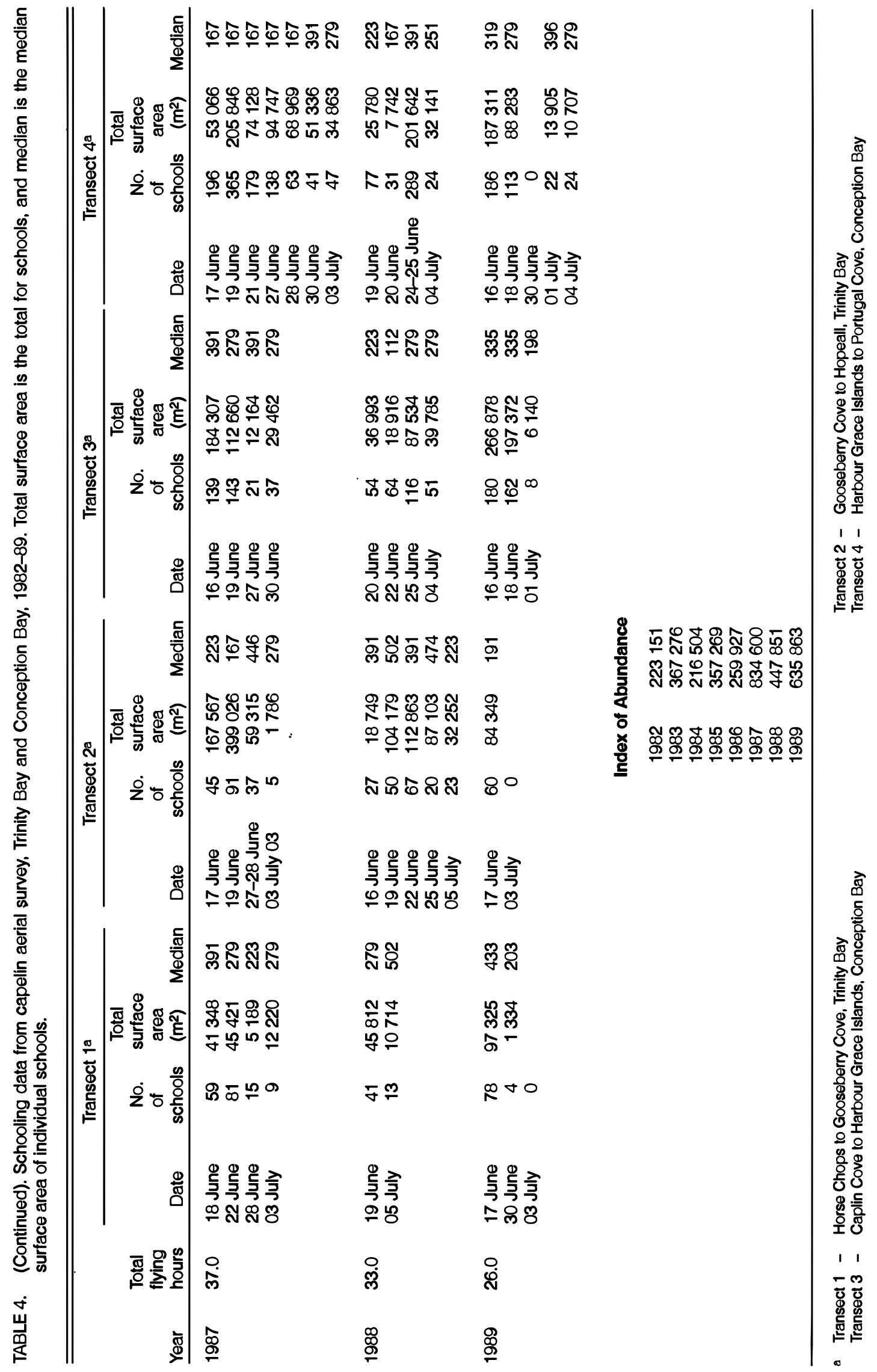


TABLE 5. Total reported capelin landings ( $\mathrm{t}$ ) for all gear, total trap net landings ( $\mathrm{t}$ ), landings plus discards ( $\mathrm{t}$ ) and days fished, from logbooks and catch rate (t/day) data for 1982-89, in Div. 3L.

\begin{tabular}{|c|c|c|c|c|c|}
\hline Year & $\begin{array}{l}\text { Total landings } \\
\text { all gear }\end{array}$ & $\begin{array}{l}\text { Total trap } \\
\text { net landings }\end{array}$ & $\begin{array}{l}\text { Logbook landings } \\
\text { and discards }\end{array}$ & $\begin{array}{l}\text { Days fished } \\
\text { from logbooks }\end{array}$ & $\begin{array}{c}\text { Catch rate } \\
\text { (t/day) }\end{array}$ \\
\hline 1982 & 27436 & 8845 & 4972 & 1630 & 3.1 \\
\hline 1983 & 25074 & 10487 & 4252 & 1236 & 3.4 \\
\hline 1984 & 33261 & 15204 & 4479 & 1535 & 2.9 \\
\hline 1985 & 25451 & 15684 & 4440 & 976 & 4.5 \\
\hline 1986 & 48427 & 26762 & 6159 & 1338 & 4.6 \\
\hline 1987 & 19503 & 12910 & 4854 & 552 & 8.8 \\
\hline 1988 & 53634 & 32970 & 6769 & 1095 & 6.2 \\
\hline 1989 & 51633 & 31541 & 6065 & 903 & 6.7 \\
\hline
\end{tabular}

may be biased up because of a labour dispute which delayed the start of the fishery so that fishermen fished at peak abundance only and a gradual increase in daily catch-rate normally observed in this fishery was thereby not recorded.

The 3-year-old capelin predominated in the inshore fishery in all years except 1984 and 1987 when 4-year-olds predominated (Table 3). The 3and 4-year-olds comprised a substantial proportion ( $>80 \%$ ) of the catch in all years while 2-year-olds and fish older than 4 years also occurred in varying proportions.

\section{Comparison of trends in abundance indices}

The trends in the two inshore indices, the trap catch-rate and the aerial survey index were correlated $(r=0.93, n=7, p=0.002)$. However, the projections of mature biomass from the acoustic surveys were not statistically correlated with either the trap catch-rate $(r=0.581, n=7, p=0.171)$ or the aerial survey index $(r=0.449, n=7, p=0.313)$. However, all three series showed lower values in the early years and generally higher values in the later years of the series. The major differences between the inshore indices and the acoustic projection occurred in 1986 and 1987. The acoustic projection increased from 1985 to 1986 and dropped in 1987, whereas the inshore series changed very little between 1985 and 1986 and declined in 1987.

\section{Discussion}

Although the time series was relatively short and there were differences in the magnitude of the annual variability in the indices and projections, the trends in the independent indicators of inshore abundance were highly correlated and generally reflected the trends in mature biomass derived from projections from the offshore surveys. The lack of statistical relationships between the acoustic projections and the two inshore series appear to have resulted from differences in 1986 and 1987. These differences may be due to the fact that fixed projection parameters were used rather than accounting for annual variability in these parameters (e.g. see Carscadden et al., 1985 for variability in proportions mature). Although the 1983 year-class appeared to be strong, it did not contribute to the inshore age-compositions during 1986 in higher proportions than did weaker year-classes at age 3 . This may have been due to slower maturation rates, as a result of either density-dependent or density-independent effects. The 1983-85 period has been identified as a cold period (Narayanan et al., MS 1992) and as a result, growth of the 1983 year-class may have been slower and maturation delayed.

In the comparison of trends in this paper, we restricted our analysis to projections from the Canadian acoustic series largely because the Canadian series has formed the basis for projections since 1986. Prior to that, projections were based on combined estimates from USSR and Canadian acoustic surveys. Also in this earlier period, surveys from both countries were conducted two years prior to the fishery with the result that projections to mature ages 3 and 4 were based on estimates of $1-$ and 2 -year-old fish. However, since 1986, projections have been performed based on Canadian estimates from surveys conducted 1 year prior to the fishery (USSR/Russian surveys have continued but timing and geographical coverage is different from the Canadian survey and the results have not been available until the following year).

In the context of the differences between the projections from the Canadian acoustic surveys and the inshore indices of abundance in 1986 and 1987, it is interesting to revisit the 1985 NAFO Scientific Council deliberations (NAFO, 1985). At that time, the projections for the fishing year 1986 used estimates of abundance from USSR and Canadian acoustic surveys conducted during 1984. The projected biomass for 1986 was lower and would have been in better agreement with the inshore indices. 
In fact, using the series of NAFO projections (which are the same as Canadian projections from 1986 to 1989) the relationships between the projections and trap catch-rate and aerial survey indices are statistically significant $(r=0.810, n=7, p=0.27 ; r=$ $0.843, n=7, p=0.17$, respectively). Intuitively, we would have predicted that the procedure used in this paper, that is, projecting only 1 year forward, would provide more accurate predictions because of the use of the most up-to-date information.

Each of the indices of abundance is subject to factors which may affect annual variability. The two fisheries-independent series (acoustics and aerial) are fixed in time because of the logistical necessities of assigning ship-time and contracting air survey flying hours well in advance of the final survey. These fixed survey times do not provide the flexibility to respond to variability in timing of inshore migration or distribution patterns. The results from these two surveys can also be influenced by environmental conditions during the survey period. For example, during early years of the acoustic survey, ice was a problem affecting survey coverage. Since acoustic survey results are a product of areal expansion calculations, low survey coverage could result in low biomass estimates. This has become less of a problem since the timing of the acoustic survey was changed from April to May beginning in 1985. Meteorological conditions can affect daily air survey coverage and long periods of poor weather may result in overall low survey coverage and underestimates of abundance, as in 1986.

The index of abundance from aerial surveys assumes that school densities are relatively constant within and between years. This assumption may have been violated since for both beach (Sleggs, 1933) and deep water (Sætre and Gjosæter, 1975) spawning, capelin were reported to occur in two types of schools near the spawning grounds. The most dense schools were those closest to the actual spawning substrate in both descriptions, and in the deep water spawning area, interfish distance within the two school types differed from three to six times. Research is planned to measure school densities acoustically during the aerial survey.

Catch rates may be affected by the same factors that influence the commercial fishery. While market forces (e.g. a market for only capelin of a particular size) will generally not influence catch rates directly since landings and discards are included in the estimation, other factors outside of scientific control can have an effect. As previously noted, the fishery was delayed in 1987 due to a labour dispute and as a result, the catch rate may have been biased upward. Opening dates of the fishery in some portions of the stock area have occasionally been varied depending on the market acceptability of the capelin. If this prevented fishing until just before the daily peak catch rates occurred, the effect on the catch rates would be similar to that in 1987, the year of the labour dispute. Since many factors affecting catch rates are beyond the scientists' control, a thorough knowledge of the fishery is invaluable when evaluating catch-rate data from the logbook program.

The relative proportions of age-groups predicted from the acoustic surveys have been reasonably reflected in the inshore age-compositions, however, there has been a general trend to predicting higher proportions of age 3 from age 2 acoustic estimates and fewer older ages. There are several possible reasons for this trend. It may be that acoustic surveys are simply not detecting older fish due to a different distribution pattern outside the survey area. In addition, the estimates of spawning mortality may be too high, especially for older fish. This possibility is evidenced from tagging experiments when mature fish tagged in one year were recovered the following year (Nakashima, 1992). The number of returns was small, thus preventing the estimation of survival rates, but given the small number of fish tagged relative to the overall population abundance and the heavy predation mortality thought to be occurring, the recovery of any tags a year after tagging is surprising and suggests that our estimates of spawning mortality may be too high.

The general agreement among projections from the acoustic surveys and the two inshore indices encourages us to continue all three. In spite of the potentially large variance associated with acoustic surveys due to such factors as target strength variations, it appears that they are describing the patterns in capelin abundance and can be used as a basis for projections. The inshore indices derived from the logbooks and the aerial survey show the same trends suggesting redundancy in research effort. However, we do not propose discontinuing either series since the success of each is subject to unrelated external factors such as market and labour disputes for the catch rates and weather for the aerial survey. Thus, both should be maintained to monitor inshore capelin abundance.

\section{Acknowledgements}

We thank technicians and summer students in the Northwest Atlantic Fisheries Centre Pelagic Section, personnel from the Hydroacoustics Development Section, employees of several aerial survey companies and fishermen who completed logbooks. J. P. Wheeler provided constructive comments on the manuscript. 


\section{References}

NAFO. 1985. Report of Scientific Council. NAFO Sci. Coun. Rep., 1985, $146 \mathrm{p}$.

1989. Report of Scientific Council. NAFO Sci. Coun. Rep., 1989, 180 p.

CAMPBELL, J. S., and G. H. WINTERS. 1973. Some biological characteristics of capelin, Mallotus villosus, in the Newfoundland area. ICNAF Redbook, 1973(III): 137144 (also ICNAF Res. Doc., No. 90, Serial No. 3048).

CARSCADDEN, J. E. 1983. Population dynamics and factors affecting the abundance of capelin (Mallotus villosus) in the Northwest Atlantic. In: Proceedings of the Expert Consultation to Examine Changes in Abundance and Species Composition of Neritic Fish Resources, San José, Costa Rica, 18-29 April 1983. FAO Fish. Rep: 789-811.

CARSCADDEN, J. E., and D. S. MILLER. MS 1980. AnaIytical and acoustic assessments of the capelin stock in Subarea 2 and Division 3K, 1979. NAFO SCR Doc., No. 13, Serial No. N045, $19 \mathrm{p}$.

CARSCADDEN, J. E., G. H. WINTERS, and D. S. MILLER. MS 1981. Assessment of the Division 3L capelin stock. NAFO SCR Doc., No. 3, Serial No. N267, 13 p.

1985. An indirect method of estimating maturation rates of cohorts of capelin (Mallotus villosus). J. Northw. Atl. Fish. Sci., 6: 135-140.

JANGAARD, P. M. 1974. The capelin (Mallotus villosus): biology, distribution, exploitation, and composition. Bull. Fish. Res. Board Can., 186: 70 p.

KIMURA, D. K., and N. A. LEMBERG. 1981. Variability in line intercept density estimates (a stimulation study of the variance of hydroacoustic biomass estimates). Can. J. Fish. Aquat. Sci., 38: 1141-1152.

NAKASHIMA, B. S. MS 1981. Sampling variation and survey design for capelin (Mallotus villosus) densities from an acoustic survey in Divisions 3LNO, 1980. NAFO SCR Doc., No. 14, Serial No. N278, 8 p.

MS 1984. Collection and interpretation of catch and effort data from the Division $3 \mathrm{~L}$ inshore capelin fishery. CAFSAC Res. Doc., No. 24, 17 p.

1992. Inferring patterns in coastal migration and stock structure of capelin (Mallotus villosus) from tag returns. Can. J. Fish. Aquat. Sci., 49: 2423-2429.

NARAYANAN, S., S. PRINSENBERG, and E. B. COLBOURNE. MS 1992. Overview of environmental conditions in NAFO Divisions $2 \mathrm{~J}+3 \mathrm{~K}$ in 1991. NAFO SCR Doc., No. 6, Serial No. N2039, 25 p.

SÆETRE, R., and J. GJOSÆETER. 1975. Ecological investigations on the spawning grounds of the Barents Sea capelin. Fiskeridir. Skr. (Havunders.), 16: 203-277.

SLEGGS, G. F. 1933. Observations upon the economic biology of the capelin (Mallotus villosus O. F. Müller). Rep. Nfld. Fish. Res. Commiss., 1(3): 1-65.

STEVENS, C. R. 1986. A hydroacoustic data acquisition system (HYDAS) for the collection of acoustic data from fish stock. Can. Tech. Rep. Fish. and Aquat. Sci., No. 1520, $73 \mathrm{p}$.

TEMPLEMAN, W. 1948. The life history of the capelin (Mallotus villosus O. F. Müller) in Newfoundland waters. Res. Bull. Nfld. Gov't. Lab., 17: 1-151.

WILLIAMSON, N. J. 1982. Cluster sampling estimation of the variance of abundance estimates derived from quantitative echosounder surveys. Can. J. Fish. Aquat. Sci., 39: 229-231. 
